\title{
Efecto de la concentración y de los componentes del medio de cultivo MS sobre la germinación in vitro de Ugni molinae
}

\author{
The effect of concentration and components of MS medium on in vitro \\ germination of Ugni molinae
}

\author{
Mario Rodríguez ${ }^{\text {a*}}$, Manuel Chacón ${ }^{a}$, Rubén Carrillo ${ }^{\text {b }}$ \\ *Autor de correspondencia: a Universidad Católica de Temuco, Facultad de Recursos Naturales, Escuela de Agronomía, \\ Rudecindo Ortega 02950, Temuco, Chile, tel.: 5645 2205536, marodrig@uct.cl \\ ${ }^{\text {b } U n i v e r s i d a d ~ d e ~ L a ~ F r o n t e r a, ~ F a c u l t a d ~ d e ~ C i e n c i a s ~ A g r o p e c u a r i a s ~ y ~ F o r e s t a l e s, ~ D e p a r t a m e n t o ~ d e ~ C i e n c i a s ~ A g r o n o ́ m i c a s ~}$ \\ y Recursos Naturales, Francisco Salazar 01145, Temuco, Chile.
}

\begin{abstract}
SUMMARY
The objective of the study was to evaluate the effect of concentration and components of the Murashige and Skoog (MS) medium on in vitro germination of Ugni molinae. Two tests were performed; in the first one, different concentrations of the MS medium were used (full-strength MS, $1 / 2$ MS, $1 / 4$ MS, $1 / 8$ MS and MS free). In the second experiment, one of the component was excluded (macro salts, micro salts or vitamins). A tetrazolium test was performed to assess viability. After the first two weeks of sowing, all treatments started germination, which was ascending until approximately 20 days, and then a slowdown was observed, which remained stable between days 40 and 60. All treatments containing any concentration of MS presented lower germination than that presented by the MS free medium, as the media containing some of its components, especially macro salts. The tetrazolium test showed $87 \%$ of viability of the seeds: the maximum germination was $42 \%$, which showed a strong latency. Germination of $U$. molinae is affected by the presence of the MS medium salts. Based on these results the use of only water and agar are recommended as the in vitro germination medium.
\end{abstract}

Key words: Myrtaceae, tissue culture, MS medium, murtilla, viability.

\section{RESUMEN}

El objetivo de este estudio fue evaluar el efecto de la concentración y los componentes del medio Murashige y Skoog (MS) sobre la germinación in vitro de Ugni molinae. Para ello se realizaron dos ensayos, en el primero, se utilizaron distintas concentraciones del medio MS (MS completo, $1 / 2$ MS, $1 / 4$ MS, $1 / 8$ MS y sin MS) y, en el segundo, se excluyó uno de sus componentes (macrosales, microsales o vitaminas). La viabilidad se determinó mediante la prueba de tetrazolio. Después de las dos primeras semanas de siembra, todos los tratamientos iniciaron la germinación, la que fue en aumento hasta aproximadamente los 20 días, luego se observó una desaceleración hasta mantenerse estable entre los 40 a 60 días. Todos los medios de cultivo que contenían alguna concentración de MS obtuvieron una germinación más baja que el medio sin MS, como también los medios que contenían algunos de sus componentes, especialmente macrosales. La prueba de tetrazolio determinó un 87 \% de viabilidad en las semillas en tanto que la germinación máxima alcanzada fue de 42 \% lo que evidenció una fuerte latencia. La germinación de U. molinae es muy sensible a la presencia de sales del medio MS razón por la cual se aconseja solo el uso de agua y agar como medio de germinación in vitro.

Palabras clave: mirtáceas, cultivo de tejidos, medio MS, murtilla, viabilidad.

\section{INTRODUCCIÓN}

La murtilla (Ugni molinae Turcz.) es un arbusto endémico de Chile, perteneciente a la familia de las mirtáceas. La planta posee tanto un sistema de propagación sexual como vegetativo lo que le proporciona una gran flexibilidad a su establecimiento y perpetuación. Las semillas se diseminan en forma endozoica, en ambiente natural germina después de cinco semanas entre los meses de octubre a diciembre y su germinación es baja respecto a otras mirtáceas (Figueroa 2003).
La germinación in vitro se utiliza con éxito para muchas especies y ha demostrado ser superior a otras técnicas como la germinación ex vitro en sustratos o con papel filtro (Ghanbari et al. 2012) para ello algunos investigadores emplean medios nutritivos en distintas concentraciones y otros a base de solo agar y agua (Gomes y Canhoto 2003, Brondani et al. 2012). En algunos casos la germinación in vitro en medios enriquecidos con sales minerales resulta apropiada especialmente en semillas pequeñas como orquídeas (Roy et al. 2011). En mirtáceas, el medio nutritivo más utilizado en germinación in vitro es el MS, no obs- 
tante, por su composición (macrosales, microsales y vitaminas), es uno de los que presenta un potencial osmótico muy negativo lo que puede dificultar la germinación de U. molinae (Cárdenas y Villegas 2002). Por lo anterior, se plantea la hipótesis que una menor concentración de medio MS provoca un aumento de la germinación en U. molinae.

La germinación in vitro permite producir plántulas asépticas como fuente de explantes y la aplicación de tratamientos químicos para romper latencia (Larson et al. 2006). El uso de embriones cigóticos maduros o de sus partes como cotiledones e hipocótilos ha sido profusamente utilizado para la producción de callos y embriones somáticos en otras mirtáceas (Correia y Canhoto 2010), otras aplicaciones es en la producción de híbridos interespecíficos (Nourissier y Monteuuis 2008), la inducción a la poliploidía (Dhooghe et al. 2011) y el desarrollo de variedades tolerantes al estrés salino (Rai et al. 2011).

Los objetivos de este estudio son evaluar el efecto de la concentración y los componentes del medio MS en la germinación in vitro de $U$. molinae como también determinar los efectos de la desinfección sobre la viabilidad.

\section{MÉTODOS}

El ensayo se realizó en el Laboratorio de Cultivo de Tejidos Vegetales de la Facultad de Recursos Naturales, Escuela de Agronomía de la Universidad Católica de Temuco, región de La Araucanía, Chile. Se realizaron dos ensayos. El primero, para determinar el efecto de las concentraciones del medio Murashige y Skoog (1962) (MS) sobre la germinación de $U$. molinae. Para ello se realizaron cinco tratamientos (MS, $1 / 2 \mathrm{MS}$, $1 / 4 \mathrm{MS}, 1 / 8 \mathrm{MS}$ y 0 MS o testigo). El segundo, para identificar el componente del medio MS que más afecta la germinación. Los tratamientos fueron: testigo (sin MS), MS, vitamina + microsales, vitamina + macrosales y macrosales + microsales.

Obtención de semillas. Las semillas utilizadas en los ensayos de germinación provenían de frutos cosechados el 2009 de una población de $U$. molinae de la localidad de Curiñanco, sector costero de Valdivia, zona Sur de Chile latitud $39^{\circ} 40^{\prime} \mathrm{S}$, longitud $73^{\circ} 21^{\prime} \mathrm{O}$. Los frutos maduros fueron colocados en maceración por 5 días, con un cambio de agua diario, al final se separó la semilla del resto de la pulpa y se secaron en cámara a $25 \pm 2{ }^{\circ} \mathrm{C}$. Las semillas secas fueron almacenadas por 6 meses a $4{ }^{\circ} \mathrm{C}$.

Desinfección de semilla. Las semillas utilizadas para el ensayo de germinación fueron desinfectadas en cámara de flujo laminar con tres soluciones en forma secuencial (fungicidas, cloro y alcohol), la solución de fungicidas contenía $2 \mathrm{~g} \mathrm{~L}^{-1}$ de Mancozeb, 0,6 g L ${ }^{-1}$ de Benomil, más unas gotas de tensoactivo Tween 20 y mantenidas bajo agitación constante por 20 minutos, luego se les adicionó hipoclorito de sodio $(\mathrm{NaOCl})$ al $2 \% \mathrm{v} / \mathrm{v}$ (cloro activo) por 10 minutos y etanol $70^{\circ}$ por 5 segundos, finalizando con tres enjuagues consecutivos de agua destilada estéril.
Preparación de medios de cultivo. Los medios de cultivo a base de sales MS o agua destilada consistieron en agua destilada gelificada con $7 \mathrm{~g} \mathrm{~L}^{-1}$ de agar microbiológico, ajustando el pH a 5,8 con 1,0 N hidróxido de potasio (KOH) y 1,0 N de ácido clorhídrico ( $\mathrm{HCl})$, utilizando como buffer para el caso del tratamiento agua-agar (0 MS) 3 mM $\mathrm{L}^{-1}$ de ácido 2-(N-morfolino) etano sulfónico (MES). Los medios fueron autoclavados por $20 \mathrm{~min}$ a $121^{\circ} \mathrm{C}$ a $1 \mathrm{~atm}$ de presión, para luego dosificar en cámara de flujo laminar $10 \mathrm{~mL}$ de medio por placas Petri de 60 x $15 \mathrm{~mm}$.

Siembra y condiciones de cultivo. Las semillas desinfectadas fueron sembradas en una cámara de flujo laminar. Se sembraron un total de 25 semillas por placa con un marco de siembra de 5 x 5 unidades. Al finalizar la siembra las placas fueron selladas con parafilm y luego incubadas en cámara de cultivo a $25 \pm 1{ }^{\circ} \mathrm{C}$, con tubos fluorescentes de luz fría blanca bajo un fotoperíodo de 16 h luz, 8 h de oscuridad y una intensidad lumínica de $50 \mu \mathrm{mol} \mathrm{m} \mathrm{m}^{-2} \mathrm{~s}^{-1}$ (tubos Philips TLD 36W/54).

Prueba de viabilidad de semillas. Se determinó la viabilidad de las semillas sin desinfectar y desinfectadas a través de la prueba de tetrazolio en cinco repeticiones de 25 semillas cada una (ISTA 2001). A las semillas se le realizó un pequeño corte de la testa en la zona micropilar y se le aplicó una solución acuosa al 1 \% de cloruro de 2, 3, 5 trifenil tetrazolio reposando en esta solución por 24 h a 30 ${ }^{\circ} \mathrm{C}$ en oscuridad. Se consideró viable aquella semilla que tenía el embrión completamente teñido de rojo.

Análisis estadísticos. Se utilizó un diseño completamente al azar para todos los tratamientos. Los gráficos fueron realizados con el programa SigmaPlot 10.0. La unidad experimental estuvo constituida por una placa con 25 semillas cada una. Cada tratamiento constó de cuatro placas. Se evaluó el porcentaje de germinación diariamente hasta los 60 días de la siembra. Los resultados se expresan como promedio \pm el error estándar. Para el caso de la viabilidad de las semillas los porcentajes de germinación se transformaron al arcoseno y se realizó un análisis de varianza (ANDEVA) con el programa SPSS versión 15.0.

\section{RESULTADOS}

La prueba de tetrazolio determinó un $87 \%$ de viabilidad para las semillas desinfectadas y un $91 \%$ en semillas no desinfectadas no presentando diferencias significativas $(P>0,05)$. Las semillas viables presentaron embriones uniformemente de color rojo intenso, sólo la zona central de la semilla, el eleosoma, no fue teñida.

En la figura 1A se aprecia la germinación durante 60 días bajo distintas concentraciones de MS. Entre los 9 y 13 días desde la siembra se concentró el inicio de la germinación para los distintos tratamientos fluctuando entre 1 y 4 \% en el primer día, luego la germinación inició un 

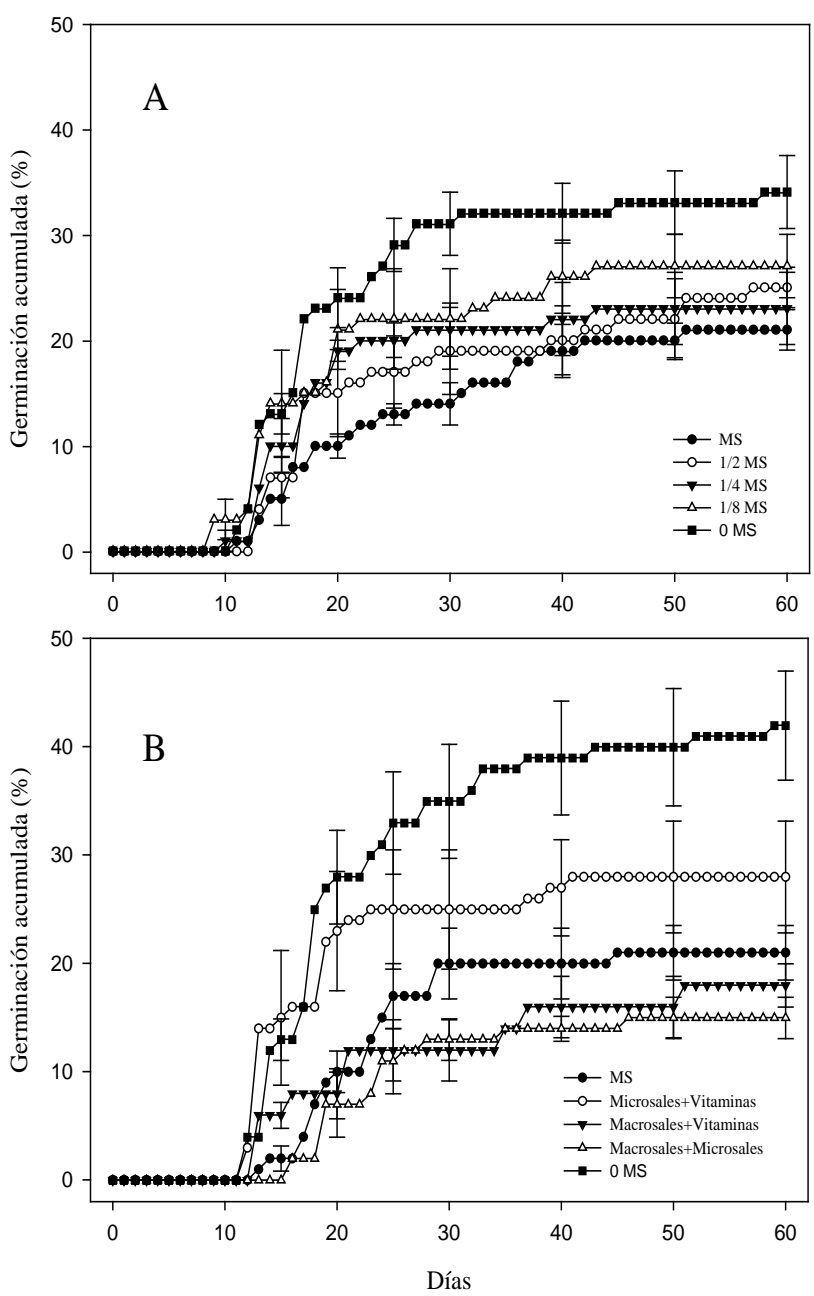

Figura 1. Porcentaje de germinación acumulada de $U$. molinae. Barras representan el error estándar. A) Efecto de la concentración del medio MS. B) Efecto de los componentes del medio MS macrosales, microsales y vitaminas.

Cumulative germination percentages of Ugni molinae. Bars represent standard errors. A) Effect of the MS medium concentration. B) Effect of components MS medium macro elements, micro elements and vitamins.

ascenso acelerado alcanzando un 10, 15, 19, 21 y $24 \%$ a los 20 días, estabilizándose en 19, 20, 22, 26 y 32 \% después de 40 días para los tratamientos MS, 1/2 MS, $1 / 4$ MS, $1 / 8$ M y 0 MS respectivamente. En este lapso de tiempo en el tratamiento control germinó más que el resto de los tratamientos que contenían medio MS, ventaja que se mantuvo hasta los 60 días, alcanzando una germinación máxima $\left(G_{\max }\right)$ de $34 \%$. El porcentaje de germinación más bajo fue para el medio MS completo con un $20 \%$, y de $25 \%$, $23 \%$ y $27 \%$ para los tratamientos $1 / 2$ MS, $1 / 4$ MS y $1 / 8$ MS, respectivamente. Por otra parte, el tiempo medio (TM) para alcanzar la germinación máxima (el momento en que se alcanza el $50 \%$ del valor $G_{\max }$ ) pasó de 16 días en el testigo a 19 días en el MS completo.

Existió una acelerada germinación entre los 12 hasta los 20 días especialmente en los tratamientos, $1 / 8 \mathrm{M}$ y 0 MS (fi- gura 1B). El tratamiento sin sales obtuvo el mayor porcentaje de germinación, alcanzando un $\mathrm{G}_{\max }$ de $42 \%$, siendo mayor a los tratamientos que contenían macrosales (MS, macrosales + vitaminas y macrosales + microsales) que presentaron los porcentajes de germinación más bajos (21, 18 y $15 \%$, respectivamente). El TM pasó de 17 a 21 días entre el medio sin sales y los medios que contenían macrosales.

\section{DISCUSIÓN}

La alta viabilidad de la semilla y la baja germinación indican una fuerte latencia como ya lo habían observado Smith-Ramírez et al. (1998) al estudiar la germinación de mirtáceas del sur de Chile, por lo que se proponen efectuar ensayos para romper latencia como la adición al medio de cultivo de citoquininas, giberelinas o fluridone (Ali-Rachedi et al. 2004). La baja diferencia entre la viabilidad antes y después de la desinfección de $4 \%$, indica que el protocolo de desinfección aplicado no afectó la viabilidad. En la semilla germinada en MS, se observó una coloración marrón entre la zona del micrópilo y el hilo la que teñía parte de la superficie del medio, fenómeno no observado en semillas germinadas sin MS. Es probable que esta exudación se deba a sustancias inhibidoras las cuales afectan la germinación. El estrés osmótico provocado por un medio rico en sales podría hacer que el metabolismo de los tejidos vegetales estimule la liberación de compuestos que son fáciles de oxidar convirtiéndose en fitotóxicos (Turkan y Demiral 2009). La inducción de síntesis de enzimas antioxidantes como catalasa, peroxidasa y superoxido dismutasa causada por estrés salino durante la germinación ha sido reportada por Sekmen et al. (2012).

Los valores de $G_{\max }$ de los medios que contienen MS (figura 1A) sugieren que la germinación de $U$. molinae es muy sensible a la presencia de sales en el medio, el efecto inhibidor de este medio de cultivo se evidencia incluso en bajas concentraciones como $1 / 8$ MS. Efectos similares fueron encontrados en otras especies atribuyendo a los nutrientes del medio MS la disminución del vigor y retardo de la germinación. Una baja germinación en MS también se ha observado al compararlo con otros medios basales que difieren en su composición y de menor concentración de sales tales como WPM, Anderson y White's (Bueno et al. 2009). La inhibición de la germinación por la presencia de sales puede deberse a efectos osmótico y tóxicos. La presencia de sales en el medio disminuye el potencial hídrico, provocando una menor disponibilidad de agua para las semillas de manera que éstas deben generar suficiente potencial osmótico para mejorar el estatus hídrico de los embriones y permitir su crecimiento (Goycokic y Saavedra 2007). El estrés osmótico también podría potenciar la síntesis de ABA que es uno de los principales causantes de la latencia en semillas (Raghavendra et al. 2010). Cárdenas y Villegas (2002) señalan que el medio MS presenta unos de los potenciales osmóticos más negativos, lo que dificulta la entrada de agua a la semilla. Otros investigadores han rela- 
cionado las altas concentraciones de sales con efectos tóxicos debido a la captación y acumulación de iones (Turkan y Demiral 2009) a lo anterior se suma el estrés oxidativo induciendo la presencia de enzimas que provocan la oxidación de lípidos proteínas y ácidos nucleicos alterando el metabolismo normal de las células (Rai et al. 2011).

Después de 16 días de siembra los tratamientos de ambos ensayos habían iniciado la germinación con un valor promedio de $10 \%$, valor que se ve poco afectado especialmente por la concentración de MS y en mayor medida por sus componentes, no obstante claramente inciden en la cinética de la germinación y $\mathrm{G}_{\max }$. Los bajos valores de $G_{\text {max }}$ se asocian a los medios que contienen macrosales (figura 1B) al quitar las macrosales del medio MS los valores de germinación se elevan. Los resultados sugieren que las macrosales son el componente del medio MS que afecta más negativamente la germinación disminuyendo de 42 a $18 \%$ respecto al tratamiento agar-agua. Al respecto, Cárdenas y Villegas (2002) señalan que de las macrosales $\mathrm{NH}_{4} \mathrm{NO}_{3}$ y $\mathrm{KNO}_{3}$ poseen un potencial osmótico muy negativo, causando desordenes fisiológicos y, por tanto, la germinación se ve afectada.

\section{CONCLUSIONES}

La germinación de $U$. molinae es muy sensible a la presencia de sales del medio MS, razón por la cual se aconseja solo el uso de agua y agar como medio de germinación in vitro. Las macrosales son el componente del medio basal que mayormente incide en su deficiente germinación. Por otra parte, esta especie presenta una elevada latencia, por lo cual se deben estudiar los mecanismos que la controlan.

\section{REFERENCIAS}

Ali-Rachedi S, D Bouinot, M Wagner, M Bonnet, B Sotta, P Grappin, M Jullien. 2004. Changes in endogenous abscisic acid levels during dormancy release and maintenance of mature seeds: studies with the Cape Verde Islands ecotype, the dormant model of Arabidopsis thaliana. Planta 219: 479-488.

Brondani G, M Araujo, B Alcântara, J Carvalho, A Gonçalves, M Almeida. 2012. In vitro organogenesis of Eucalyptus grandis: effects of boron and calcium. Acta Scientiarum Agronomy 34(4): 403-411.

Bueno M, C Alzugaray, G Giubileo, C Severino, N Carenvale. 2009. Evaluación de la calidad fisiológica de semillas de Maytenus vitis-idaea cultivadas in vitro. Bosque 30(3): 146-150.

Cárdenas M, A Villegas. 2002. Potencial osmótico del medio de cultivo con diferentes componentes para la propagación in vitro. Revista Fitotecnia Mexicana 25: 213-217.
Correia S, J Canhoto. 2010. Characterization of somatic embryo attached structures in Feijoa sellowiana Berg. (Myrtaceae). Protoplasma 242: 95-107.

Dhooghe E, K Van Laere, T Eeckhaut, L Leus, J Van Huylenbroeck. 2011. Mitotic chromosome doubling of plant tissues in vitro. Plant Cell Tissue and Organ Culture 104: 359-373.

Figueroa J. 2003. Seed germination in temperate rain forest species of southern Chile: chilling and gap dependency germination. Plant Ecology 166: 227-240.

Ghanbari T, B Hosseini, Z Jabbarzadeh. 2012. Improving Salvia sclarea L. seed germination under in vitro condition. International Journal of Agriculture: Research and Review 2(S): 1051-1058.

Gomes F, J Canhoto. 2003. Micropropagation of Eucalyptus nitens Maiden (Shining gum). In vitro Cellular \& Development Biology - Plant 39: 316-321.

Goycokic V, G Saavedra. 2007. Algunos efectos de la salinidad en el cultivo del tomate y prácticas agronómicas de su manejo. IDESIA 25(3): 47-58.

ISTA (International Seed Testing Association). 2001. International rules for seed testing 2001. Seed Science and Technology 29(2): 28-29.

Larson C, C Gómez, M Sánchez, D Ríos. 2006. Inducción de caulogénesis indirecta en Eucalyptus globulus. Bosque 27(3): 250-257.

Murashige T, F Skoog. 1962. A revised medium for rapid growth and bio assays with tobacco tissue cultures. Physiologia Plantarum 15: 473-497.

Nourissier S, O. Monteuuis. 2008. In vitro rooting of two Eucalyptus urophylla x Eucalyptus grandis mature clones. In Vitro Cellular and Developmental Biology Plant 44: 263-272.

Raghavendra A, V Gonugunta, A Christmann, E Grill. 2010. ABA perception and signalling. Trends in Plant Science 15(7): 395-401.

Rai M, R Kaliaa, Singha, M Gangolaa, A Dhawana. 2011. Developing stress tolerant plants through in vitro selection - an overview of the recent progress. Environmental and Experimental Botany 71: 89-98.

Roy A, R Patel, V Patel, S Sajeev, B Deka. 2011. Asymbiotic seed germination, mass propagation and seedling development of Vanda coerulea Grigg ex. Lindl. (Blue Vanda): An in vitro protocol for an endangered orchid. Scientia Horticulturae 128: 325-331.

Sekmen A, I Turkan, Z Tanyolac, C Ozfidan, A Dinc. 2012. Different antioxidant defense responses to salt stress during germination and vegetative stages of endemic halophyte Gypsophila oblanceolata Bark. Environmental and Experimental Botany 77: 63-76.

Smith-Ramírez C, J Armesto, J Figueroa. 1998. Flowering, fruiting and seed germination in Chilean rain forest myrtaceae: ecological and phylogenetic constraints Plant Ecology 136: 119-131.

Turkan I, T Demiral. 2009. Recent developments in understanding salinity tolerance. Environmental and Experimental Botany 67: 2-9. 